\title{
Coal Mine Safety Influence Factors Causality Analysis and Function Relationship Construction Based on System Dynamics
}

\author{
Chen Jing $^{1} \quad$ Yang Yongjie $^{1} \quad$ Cao Qinggui $^{1}$ \\ (1. National Key Laboratory of Mine Disaster Prevention and Control, Shandong \\ University of Science and Technology, Qingdao, Shandong 266590)
}

\begin{abstract}
The paper analyses the main features of coal mine system, and construct coal mine safety system dynamics model by using the system dynamics theory from the angle of enterprise' safety management level. And it also make data quantitative analysis about the model by non-linear regression method, draw the curve model that can reflect the dynamic change of the various system elements by using system dynamics VESIM software. It provide scientific basis for actual coal mine system safety management, and has an important guiding significance.
\end{abstract}

Keywords: coal mine; influence factors; function relationship; system dynamics

\section{Overview}

Coal mining system is underground work, geological conditions complex, production process tedious, natural hazards happened frequently, mechanization degree low, personnel structure complex, underground work time long, labor intensity, so, the coal mine safety management system is very complex. At present, most of the coal mining enterprises in our country use safety management method to manage qualitative from the static point of management constraints, Integrity, systematic and scientific is not strong. So, Combining with the characteristics of coal mine system, based on system dynamics theory, the paper construct coal mine safety system dynamics model, and made quantitative data processing by nonlinear regression prediction model, provides a scientific basis for the actual coal mine safety management.

\section{Coal mine safety factors causality analysis}

In Safety Economics, the level of safety management is measured by "safety efficiency", reflected by the ratio of safety input and output ${ }^{[1]}$, and in the 
actual production process, it can also be used to embody intuitively by "coal mine accident frequency". The accident is the common results that the three factors of person, things, environment interact with each other, to some extent, the state of these three factors is decide by safety input, and then their different state meeting caused the accident results, also to determine how much "safe production" in the enterprises. Based on the above analysis, It can achieve the purpose that reduce the accident total probability by reducing the three factors' occurrence probability, and changing safety investment object and quantity. So, under the condition that annual output is normal and coal mine prices is stable, the enterprise safety benefit will increase, safety management level will be high, conversely, it is low. Therefore, the paper use system causality diagram to express the multiple positive and negative feedback relationship among all the elements (as shown in Figure 1).

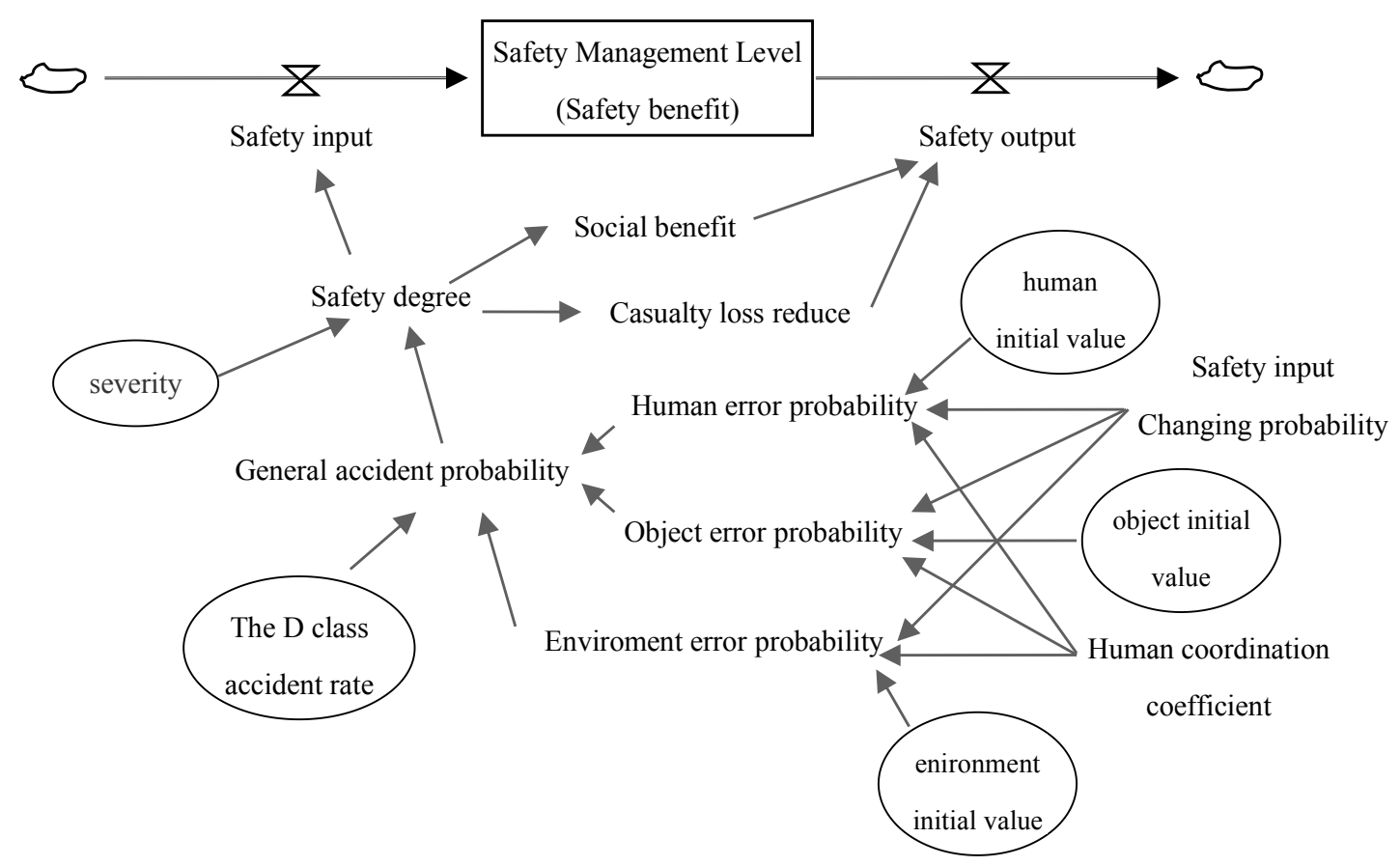

Fig1: Coal mine safety system causality relationship for system dynamics

\section{Coal mine influence factors function relationship construction}

( I ) Accident loss

$$
\begin{aligned}
\text { Accident loss }= & \text { Accident Direct loss }+ \text { Accident Indirect loss } \\
& =(1+\mathrm{K}) * \text { Accident Direct loss }
\end{aligned}
$$




$$
=(1+\mathrm{K}) \times\left(\mathrm{VL} \times \sum_{i=1}^{3} K_{i} \bullet N_{i} \quad\right)
$$

$K_{i}{ }_{\ldots}$ class "i" accident form coefficient;

$N_{i} \_$numbers of injury person in class "i”;

$\mathrm{V}_{\mathrm{L}} \longrightarrow$ basic economic consumption, usually using $150 \mathrm{RMB}$.

$\mathrm{K}$ —accident loss coefficient, usually using 4.

\section{( II) Social value}

Security value-added output $=$ safety production contribution rate $*$ total output value;

Production contribution rate $=$ Security investment $/$ Production investment.(3)

(III) Quantization for the proportion of human error and object misconduct; the each kind accident class " $\mathrm{C}$ " is that caused by human error and environment degradation; the class The class " $\mathrm{A}$ " accident is that accident " $\mathrm{D}$ " is that caused by human error, is directly caused by human error; the object misconduct, environment class " $\mathrm{B}$ " accident is that caused by degradation in the same time. the class "A" accident ratio $=\left(\sum\right.$ the class " $\mathrm{A}$ " accident ratio in each year $) /$ The total number of years;

the class " $\mathrm{B}$ " accident ratio $=\left(\sum\right.$ the class " $\mathrm{B}$ " accident ratio in each year $) /$ The total number of years;

the class " $\mathrm{C}$ " accident ratio $=\left(\sum\right.$ the class " $\mathrm{C}$ " accident ratio in each year $) /$ The total number of years;

the class " $\mathrm{D}$ " accident ratio $=\left(\sum\right.$ the class " $D$ " accident ratio in each year $) /$ The total number of years.

(IV) Accident total probability

accident total probability $=$ the accident ratio of class " $\mathrm{A}$ " * human reason probability + the accident ratio of class " $\mathrm{B}$ " * (human reason probability + things reason probability ) + the accident ratio of class " $\mathrm{C}$ " * (human reason probability + environment reason probability ) + the accident ratio of class " $D$ " * (human reason probability + things reason probability + environment reason probability $)$. 
(V) Severity degree

severity of Accident loss $\approx$ The death rate per million tons $=$ (the number of death, Seriously injured and Minor injuries)* $106 /$ Coal production(t).

(VI) Safety degree

safety degree $=10$ - accident total probability * severity degree;

(VII) Safety input changing rate

safety input changing rate $=\mid($ Safety input value - Safety input value of last year $) /$

Safety input value of last year I;

(VIII) Human factor's probability, thing factor's probability, and environment factor's probability

human factor's probability $\approx$ times of human error directly per year / ( times of human error directly per year + times of things error per year + times of environment error per year);

thing factor's probability $\approx$ times of things error per year / ( times of human error per year + times of things error per year + times of environment error per year $) ;(13)$

environment factor's probability $\approx$ times of environment error per year / ( times of human error directly per year + times of things error per year + times of environment

$$
\text { error per year ); }
$$

changing rate for human factor's probability $=\mid$ (human factor's probability one year - human factor's probability last year) / human factor's probability last year | ; (15) changing rate for things factor's probability $=\mid$ (things factor's probability one year things factor's probability last year) / things factor's probability last year |;(16)

changing rate for environment factor's probability $=\mid$ (environment factor's probability one year - environment factor's probability last year) / environment factor's probability last year $\mid$.

(IX)Human coordination coefficient

In the model, human coordination degree is a random variable, it can be reflected by a random function $\mathrm{T}=$
RANDOM UNIFORM (m, x, s), so, generate a random function between' $\mathrm{M}-\mathrm{X}$ ', and ' $\mathrm{s}$ ' is the initial value. 
( X Human initial value, things initial value, environment initial value

It refers to the initial value of human reason probability, things reason probability, environment reason probability. It is any constant among ( 0 , 1).

\section{System dynamics curve model}

Based on the model that have been established above, using the method of nonlinear regression to make macroscopic analysis for coal mine, it can get the coal mine safety elements system dynamics curve relationship model by VESIM software in simplified Chinese version, As shown in Figure 2. the model can reflect the curve general trends.

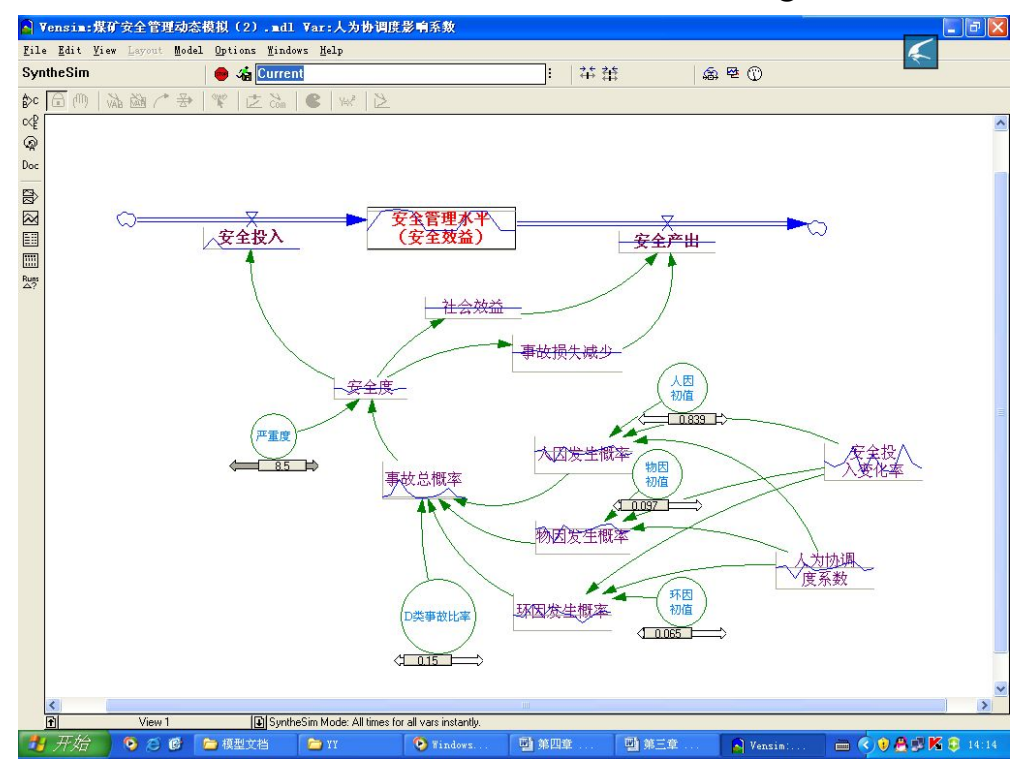

Fig2: System dynamics model graph

\section{Conclusion}

The main research results are as follows. First of all, from the point of safety management level, it determined variable factors that impacted safety management level, analyzed the causal and circulation relationship during the operational process of coal mine safety management. Secondly, using system dynamics theory to build coal mine safety system dynamics model, find out the quantitative method of the variable factors in the model. Finally, established the corresponding mathematical model by using the nonlinear regression prediction method, and provided the scientific basis for coal mine enterprise safety management. 


\section{References}

[1] Luo Yun. Safety economics [M]. Beijing. chemical industry press, 2004.

[2] Liang Meijian. Coal enterprises safety investment safeguard mechanism and system dynamics analysis[J].Beijing. Chinese journal of safety science, 2010,20(1):125-158.

[3] He Gang, Zhang Guoshu, Chen Qinghua, Qiao Guotong. System dynamics simulation analysis of Coal mine safety management level impact factor $\quad[\mathrm{J}]$.Mining Safety, 2010,(5):147-150.

[4] Shi Shiliang. Applied research about Mine safety nonlinear dynamics appraisal model[D]. ChangSha, HuNan Province: Central south university, 2000.

[5] Li Zhicheng, $\mathrm{Hu}$ Bin, Fu Xiaohua, Xiao-Guang Gong. Management system theory and application of qualitative simulation. Beijing. Science Press ,2005,9-10. 